\title{
The association between obesity and social exclusion in middle-aged and older adults: findings from a nationally representative study in Germany
}

André Hajek *i] and Hans-Helmut König

\begin{abstract}
Background: There is a lack of studies that focus explicitly on the association between social exclusion and obesity. The aim of the present study was to identify whether social exclusion is associated with obesity in older adults, and whether this association is moderated by sex.

Methods: Data were derived from wave 5 (2014) of the German Ageing Survey - a representative sample of individuals residing in private households aged 40 and over in Germany. A validated scale developed by Bude and Lantermann was used to assess social exclusion. Individuals with body-mass-index $\geq 30 \mathrm{~kg} / \mathrm{m}^{2}$ were classified as being obese. Multiple linear regressions were applied in this study.

Results: Linear regressions showed that social exclusion was not associated with obesity in the total sample and in men, whereas women with obesity were less socially excluded than women without obesity $(\beta=-.06, p=.02)$. The corresponding interaction term (sex x obesity) achieved statistical significance $(p=.03)$.

Conclusions: Our findings emphasize the negative association between social exclusion and obesity in women, but not men, highlighting the complex interplay between social factors and excess weight in individuals aged 40 and above. Future longitudinal studies are needed to clarify this relationship in further detail.
\end{abstract}

Keywords: Body mass index, Obesity, Social isolation, Adult

\section{Background}

Obesity is an important risk factor for mortality and morbidity [1]. Moreover, it is associated with a tremendous financial burden [2]. It has been shown that obesity is highly prevalent in middle aged individuals [3] and individuals aged 75 years and over [4]. It has also been demonstrated that obesity is associated with a decreased quality of life, higher disability, as well as perceived discrimination. These factors can result in feelings of social exclusion. For example, Corica et al. [5] stated that a patient-centered approach that aims at lowering the social exclusion of older adults is required to maintain health-related quality of life in individuals with obesity. Socially excluded individuals can be defined as "people

\footnotetext{
* Correspondence: a.hajek@uke.de

Department of Health Economics and Health Services Research, University Medical Center Hamburg-Eppendorf, Hamburg, Germany
}

not being involved in different areas of life and their community, eg being unemployed and having a limited social network" [6]. It can lead to distress and anxiety [7].

There are some studies that examine the relation between loneliness or social relationships and obesity. For example, Schumaker et al. [8] found that individuals with obesity had higher loneliness scores than individuals without obesity. Women with obesity scored higher than women without obesity, whereas differences in men with and without obesity were not significant. Moreover, Oliveira et al. [9] examined whether social relationships influenced the incidence of obesity. They found that a lack of emotional support and social relations was associated with an increased incidence of obesity among men. Another study showed that loneliness was positively related to body-mass-index (BMI) values among 182 Spanish women aged 40 to 65 [10].

(c) The Author(s). 2018 Open Access This article is distributed under the terms of the Creative Commons Attribution 4.0 International License (http://creativecommons.org/licenses/by/4.0/), which permits unrestricted use, distribution, and reproduction in any medium, provided you give appropriate credit to the original author(s) and the source, provide a link to the Creative Commons license, and indicate if changes were made. The Creative Commons Public Domain Dedication waiver (http://creativecommons.org/publicdomain/zero/1.0/) applies to the data made available in this article, unless otherwise stated. 
There are also studies that focus on the relation between social relationships/social support and weight management among middle aged or aged individuals [11-14]. However, there is a lack of studies that explicitly focus on the association between social exclusion and obesity. Thus, based on a nationally representative sample among individuals in the second half of life (40 years and over), the aim of the present study was to determine whether social exclusion is associated with obesity in older adults, and whether this association is moderated by sex.

Based on previous findings [8, 9], we hypothesize that individuals with obesity are more socially excluded than individuals without obesity. A possible explanation for this may be that individuals with obesity feel like outsiders [8]. A further explanation may be that they are stigmatized because they do not meet social norms of attractiveness [15]. It is conceivable that obesity impairs social relationships, both in terms of quantity and quality, as well as participation in social activities, because of possible feelings of self-consciousness [8]. As a result, individuals with obesity may feel socially excluded. However, individuals with obesity may befriend other individuals with obesity to better cope with life [8]. Notwithstanding, we assume that these strategies may reduce, but not entirely offset the positive association between social exclusion and obesity, i.e. individuals with obesity may have higher social exclusion scores. Stratified by sex, we hypothesize that the association between obesity and social exclusion is more pronounced in women. Particularly among women, thinness is an important dimension of attractiveness due to, eg, exposure to the media [16]. Hence, it appears plausible that this association is stronger in women than men. Knowledge about an association between social exclusion and obesity, and whether this association is moderated by sex, may be important in assisting individuals at risk for social exclusion.

\section{Methods}

\section{Sample}

For the present study, data from the fifth wave (2014) of the German Ageing Survey (DEAS, "Deutscher Alterssurvey") were analyzed. The DEAS is a representative cross-sectional and longitudinal survey of the community-dwelling population aged 40 and above in Germany. This survey is organised by the German Centre of Gerontology (DZA, "Deutsches Zentrum für Altersfragen") and is funded by the Federal Ministry for Family Affairs, Senior Citizens, Women and Youth (BMFSFJ). This survey started in 1996, covering a wide spectrum of topics ranging from social exclusion to the meaning of ageing. Register sampling of the individuals was used, disproportionally stratified by age, gender and location.
The primary inclusion criterion was that individuals had to be 40 years and above. Further inclusion criteria for first time participants were (1) born between 1929 and 1974 and (2) living in private household (which excludes individuals living in institutionalized surroundings). Inclusion criteria for panel participants were (1) one or more valid interviews before (1996, 2002, 2008 or 2011), (2) written consent (willingness to participate in the panel) and (3) still alive as well as not living abroad.

A national representative baseline sample was drawn in the waves 1, 2 (2002), 3 (2008) and 5 and was followed up afterwards. The fourth wave (2011) was a pure panel survey, which means that only individuals who had already taken part before were re-interviewed. In wave 5, while approximately 6000 individuals took part for the first time, more than 4000 individuals were re-interviewed. The response rate was 33\%, which is quite similar compared to other large survey studies conducted in Germany [17]. Refusal to participate and bad health condition were main reasons for lack of follow-up data. Among the 'refusal to participate' group, a 'general refusal to participate' was the main reason. Among this group, other reasons were 'not interested' or 'no time/too long'. Other reasons were negligible. For detailed figures (depending on the subsample), please see [18]. Further details with regards to the DEAS study, such as sample selection or panel mortality, have been provided elsewhere $[18,19]$, but are also discussed in the discussion section (strengths and limitations) of this paper. Social exclusion was only assessed in the fifth wave. Thus, only data from the fifth wave were used in the current cross-sectional analysis.

The study was conducted according to the principles expressed in the Declaration of Helsinki. Prior to the interview, written informed consent was given. Please note that an ethical statement for this study was not necessary as the criteria for requiring an ethical statement were not met (risk for the respondents, lack of information about the aims of the study, examination of patients). For example, invasive methods were not used.

\section{Dependent variable}

A scale generated by Bude and Lantermann [20] was used to assess social exclusion. It consists of four items (ranging from 1 = "strongly agree" to 4 = "strongly disagree"): "I am worried to be left behind", "I feel like I do not really belong to society", "I feel that I am left out", and "I feel excluded from society". According to the DEAS guidelines, the scale reflects the mean of at least two required (recoded) valid items. Thus, it was treated as continuous variable, which is in accordance with previous research [21]. Higher values represent higher perceived social exclusion. In our study, Cronbach's Alpha was .88. 


\section{Independent variables}

The variable of interest was the presence of obesity. Height (meter) and weight (kg), both self-reported, were used to calculate BMI (weight divided by height-squared). Individuals with $B M I \geq 30 \mathrm{~kg} / \mathrm{m}^{2}$ were classified as being obese (0 otherwise). Moreover, potential confounders were identified and controlled for. As socioeconomic covariates, we included age, marital status (married, living together with spouse; others (married, living separated from spouse; single; divorced; widowed), and individual monthly net equivalent income (OECD scale). With respect to lifestyle factors, smoking behavior (daily smoker; casual smoker; former smoker; non-smoker), frequency of sports activities as well as alcohol intake (in both cases, categories were: 'never,' 'rarer than once a month', 'one to three times a month,' 'once a week, 'several times a week', and 'daily') were identified as possible confounders and controlled for. Furthermore, self-rated health status (from $1=$ "very good" to $5=$ "very bad") and the number of chronic illnesses (eg, bad circulation; respiratory problems, asthma, shortness of breath; cancer; diabetes; eye problems, vision impairment; ear problems, hearing problems) were included as covariates.

The covariates were selected based on theoretical assumptions and empirical findings. While the association between obesity and self-rated health as well as chronic illnesses may appear plausible, the other associations may require further explanation. For example, it has been shown that lifestyle factors (smoking behavior, frequency of sports activities and alcohol intake) are strongly associated with obesity [22-25]. Physical activity may also be a factor leading to lower social exclusion, particularly in old age. Moreover, it has been demonstrated that income and educational level are associated with obesity [26]. Since we aimed at identifying the ceteris paribus relationship between obesity and social exclusion, we adjusted for these covariates.

In sensitivity analysis, employment status (employed; retired; other: not employed), and depression (CES-D $\geq$ 18 [27]) were used.

\section{Statistical analysis}

First, sample characteristics were computed to describe the study participants. Second, multiple linear regressions were used to analyze the association between social exclusion and BMI. Third, because it has been demonstrated that social factors differ between men and women in higher age [28], regressions stratified by gender were conducted. Whether sex moderates the association between social exclusion and BMI was also tested. The statistical significance was determined with $p<0.05$. Stata 14.0 (StataCorp, College Station, Texas, USA) was used to perform the analyses.
In all regressions, multicollinearity was tested for, using the variance inflation criterion. The largest variance found was 3.16, indicating that a problem with multicollinearity was not present. In addition, the White test for heteroscedasticity in the error distribution was conducted. In all regressions, the test statistics (for example, in the total sample: White's general test statistic $=558.95, p<0.001)$ lead to the rejection of the null hypothesis of homoscedasticity. Thus, robust standard errors were used in our study.

As there is evidence that perceived weight discrimination differs between obese classes [29], sensitivity analysis was conducted differentiating between these groups (please see the results section for further details).

\section{Results}

\section{Sample characteristics}

Sample characteristics are depicted in Table 1. In sum, 7838 participants (mean age: 64.5 years \pm 11.2 years; $50.4 \%$ were aged 65 years and above) provided information about social exclusion. The mean social exclusion score was 1.6 ( \pm 0.6 ; ranging from 1 to 4 ). Approximately one half were female (51.0\%). As for marital status, $70.0 \%$ of the individuals were married and living together with spouse. About 21.2\% were classified as being obese $\left(B M I \geq 30 \mathrm{~kg} / \mathrm{m}^{2}\right)$.

\section{Regression analysis}

The results of the multiple regressions are shown in Table 2 (first column: total sample; second column: men; third column: women). $\mathrm{R}^{2}$ values were $.11, .13$, and .09 , respectively. After adjusting for various potential confounders (regression coefficients not shown here, but available upon request), linear regressions showed that while social exclusion was not associated with obesity in the total sample and in men, women with obesity were less socially excluded than women without obesity $(\beta=-.06, p=.02)$. In addition, it was tested whether sex moderates the association between social exclusion and BMI. Actually, the corresponding interaction term (sex $\mathrm{x}$ obesity) was significant $(p=.03)$.

In sensitivity analysis (not shown here, but available upon request), survey weights were used in order to ensure the representativeness of the data. Results remained almost the same. For example, women with obesity were less socially excluded than women without obesity $(\beta=-.07, p=.03)$. The interaction term remained significant $(p=.04)$.

We also tested whether our findings were dependent on the statistical approach chosen. Therefore, linear regressions were replaced by ordered probit regressions. In terms of significance, our results remained virtually the same. 
Table 1 Sample characteristics $(n=7838)$

\begin{tabular}{|c|c|c|}
\hline & N/Mean & $\% /(\mathrm{SD})$ \\
\hline Gender: Female & 3996 & $51.0 \%$ \\
\hline Age in years & 64.4 & 11.2 \\
\hline $\begin{array}{l}\text { Marital status: married and living together } \\
\text { with spouse }\end{array}$ & 5476 & $70.0 \%$ \\
\hline Monthly net equivalent income in Euro & 1943.7 & 1382.3 \\
\hline Weight classification: Obesity (BMI $\geq 30 \mathrm{~kg} / \mathrm{m}^{2}$ ) & 1634 & $21.2 \%$ \\
\hline Smoking status: Daily & 1076 & $13.8 \%$ \\
\hline - Yes, sometimes & 309 & $4.0 \%$ \\
\hline - Not anymore & 2879 & $37.1 \%$ \\
\hline - Never been smoker & 3500 & $45.1 \%$ \\
\hline Consumption of alcohol: Daily & 925 & $12.0 \%$ \\
\hline - several times a week & 1882 & $24.4 \%$ \\
\hline - once a week & 1244 & $16.1 \%$ \\
\hline - one to three times a month & 938 & $12.1 \%$ \\
\hline - less frequently & 1862 & $24.1 \%$ \\
\hline - never & 874 & $11.3 \%$ \\
\hline Physical activity: Daily & 663 & $8.5 \%$ \\
\hline - several times a week & 2136 & $27.3 \%$ \\
\hline - once a week & 1427 & $18.2 \%$ \\
\hline - one to three times a month & 592 & $7.5 \%$ \\
\hline - less frequently & 918 & $11.7 \%$ \\
\hline - never & 2101 & $26.8 \%$ \\
\hline $\begin{array}{l}\text { Self-rated health } \\
\text { (from } 1=\text { "very good" to } 5=\text { "very bad") }\end{array}$ & 2.5 & 0.8 \\
\hline Number of physical illnesses & 2.6 & 1.9 \\
\hline $\begin{array}{l}\text { Social exclusion (from } 1 \text { to } 4 \text {; higher } \\
\text { values reflect higher social exclusion) }\end{array}$ & 1.6 & 0.6 \\
\hline Social exclusion: 1 & 2350 & $30.0 \%$ \\
\hline$>1$ and $<2$ & 2754 & $35.1 \%$ \\
\hline$\geq 3$ and $<4$ & 2397 & $30.6 \%$ \\
\hline$\geq 4$ and $<5$ & 299 & $3.8 \%$ \\
\hline 5 & 38 & $0.5 \%$ \\
\hline
\end{tabular}

Social exclusion was assessed using a scale developed by Bude and Lantermann [20]. Range for number of physical illnesses was 0 to 11
In further sensitivity analysis, it was tested whether the association between obesity and social exclusion varied by employment status, marital status, depression or age. However, none of the interaction terms achieved statistical significance.

In another sensitivity analysis, the definition of obesity was modified to only include individuals with $\mathrm{BMI} \geq$ $30 \mathrm{~kg} / \mathrm{m}^{2}$ and $\mathrm{BMI}<40 \mathrm{~kg} / \mathrm{m}^{2}$ in order to exclude Obese Class III individuals, which may strongly affect results. In terms of effect sizes and significance, findings remained virtually the same. In further sensitivity analysis, the definition of non-obesity was restricted to individuals with $B M I>18.5 \mathrm{~kg} / \mathrm{m}^{2}$ and $\mathrm{BMI}<30 \mathrm{~kg} / \mathrm{m}^{2}$. Again, findings remained almost the same. Thus, findings were not driven by underweight individuals.

In another sensitivity analysis, BMI was classified as: (0) $\mathrm{BMI}<30 \mathrm{~kg} / \mathrm{m}^{2}$, (1) $30 \mathrm{~kg} / \mathrm{m}^{2} \leq \mathrm{BMI}<40 \mathrm{~kg} / \mathrm{m}^{2}$ and $\mathrm{BMI}<40 \mathrm{~kg} / \mathrm{m}^{2}$ as well as (2) BMI $\geq 40 \mathrm{~kg} / \mathrm{m}^{2}(63 \mathrm{men}$; 93 women). When compared with our main models, findings remained almost the same. Women with obesity (Obese class I and II) were less socially excluded than women without obesity $(\beta=-.05, p=.04)$. Women with obesity (Obese class III) were not less socially excluded than women without obesity $(\beta=-.13, p=.09)$.

We also tested whether differences exist between individuals with obesity and (i) individuals with normal weight as well as (ii) overweight individuals. Again, women with obesity were less socially excluded than women with normal weight $(\beta=-.07, p=.02)$. However, women with obesity were not less socially excluded than women with overweight $(\beta=-.05, p=.06)$. Apart from that, other significant differences between the groups were not observed.

Stratified by age (younger than 65 years; aged 65 years and above), women with obesity younger than 65 years were less socially excluded than women without obesity younger than 65 years $(\beta=-.08, p=.01)$, whereas women with obesity aged 65 years and above were not less socially excluded than women without obesity aged 65 years and above $(\beta=-.04, p=.35)$.

Table 2 Determinants of social exclusion (German Ageing Survey, 2014)

\begin{tabular}{llll} 
& $(1)$ & $(2)$ & $(3)$ \\
& Social exclusion - Total sample & Social exclusion - Men & Social exclusion - Women \\
\hline Potential confounders & $\checkmark$ & $\checkmark$ & $\checkmark$ \\
Obesity (BMl $\geq 30 \mathrm{~kg} / \mathrm{m}^{2}$; Ref.: Non-obese) & $-0.03(0.02)$ & $0.01(0.02)$ & $-0.06^{*}(0.03)$ \\
Constant & $2.50^{* * *}(0.06)$ & $2.39^{* * *}(0.08)$ & $2.642^{* * *}(0.09)$ \\
Observations & 7041 & 3532 & 3509 \\
$\mathrm{R}^{2}$ & 0.11 & 0.13 & 0.09 \\
\hline
\end{tabular}

Potential confounders include age, family status, monthly net equivalent income, smoking status, alcohol consumption, frequency of sports activities, self-rated health and number of chronic illnesses. Beta-Coefficients are reported; Cluster-robust standard errors in parentheses. ${ }^{* * *} p<0.001,{ }^{* *} p<0.01,{ }^{*} p<0.05,+p<0.10$. Observations with missing values were dropped (listwise deletion). Social exclusion was assessed using a scale developed by Bude and Lantermann [20] 


\section{Discussion}

\section{Main findings}

Based on a large, population-based sample of individuals in the second half of life, linear regressions showed that social exclusion was not associated with obesity in the total sample and in men, whereas women with obesity were less socially excluded than women without obesity, with significant interaction (sex $\mathrm{x}$ obesity).

\section{Relation to previous studies and possible explanations}

To date, only a few studies have attempted to determine the association between obesity and factors such as loneliness $[8,9]$, and there have not been any studies that have sought to determine whether there is an association between obesity and social exclusion. We acknowledge that loneliness and social exclusion are correlated. However, they do not measure the same concepts [30]. Individuals feeling lonely may not see themselves as socially excluded and vice versa [31]. These studies have demonstrated that individuals with obesity tend to have higher loneliness scores. Based on these studies, we hypothesized that individuals with obesity have higher social exclusion scores than individuals without obesity. Moreover, it was hypothesized that the association between obesity and social exclusion would be more pronounced in women. However, in contrast to our initial expectations and to previous studies, social exclusion was not associated with obesity in the total sample and men, but there was an association between social exclusion and obesity in women. However, the association in women was in the opposite direction to what was expected. We found that women with obesity were less socially excluded than women without obesity (at least in middle age). Moreover, gender moderates the association between obesity and social exclusion.

In the current study, the non-significant association between social exclusion and obesity among men may be explained by the fact that positive effects (eg, friendship with other individuals with obesity) counterbalance negative effects of obesity (eg, impaired social relationships or feelings of social inhibition). Given the fact that women with obesity face multiple social and economic disadvantages [32], it is somewhat surprising that women with obesity were less socially excluded than women without obesity in our study. A possible explanation for this association may be that women with obesity aged 40 and over have a positive perception of their social relationships. They may feel appreciated by their friends and acquaintances. In other words, a woman with obesity in the second half of life may feel accepted the way she is (regardless of social norms of attractiveness). Furthermore, a higher age and being female were associated with more positive views about obesity in the Swedish general population [33]. Another study has shown that children with obesity in particular, rather than adults or senior citizens are at a higher risk of being confronted with stigmatization [15]. These results $[15,33]$ may indicate that older women with obesity may be more accepted by (female) friends.

It is also conceivable that our findings may be (at least partially) explained by self-selection: Women scoring low in social exclusion are more likely to become obese (affected by unobserved factors such as extraversion). Thus, longitudinal studies investigating the relation between social exclusion and obesity are urgently needed in order to control for time-constant unobserved factors.

\section{Strengths and limitations}

As one of the first studies in this area, we demonstrate that social exclusion and obesity are negatively associated in women, but not men. Data were gathered from a large, population-based sample of individuals in the second half of life. Social exclusion was quantified using a scale with very good psychometric properties. Several potential confounders were used in the analysis. Self-rated BMI was used. It is worth nothing, that as a consequence, it is likely that BMI among the sample was underestimated [34] although this would depend on how the social network affects self-perception of weight. In addition, the caloric intake was not measured in the DEAS study. Furthermore, personality characteristics such as extraversion or openness to experience may be important in the relation between social exclusion and obesity. Self-selection bias may be a concern in the DEAS study. More specifically, it has been shown that participation rates are lower in women, oldest age and individuals residing in large cities [19]. However, it has also been shown that this bias may be relatively small in this survey [19]. Actually, the distribution of sociodemographic attributes (e.g., marital status and educational level) is very close to the distribution to the distribution within the German population [19]. The present study is a cross-sectional one. It could be argued that the causal direction of this relationship (social exclusion and obesity) is bidirectional (development of obesity induced by feelings of loneliness or social exclusion). This is in accordance with the social control theory [35]. Thus, future studies based on longitudinal data are required to clarify this relation.

\section{Conclusion}

Our findings emphasize a negative association between social exclusion and obesity in women, but not men, highlighting the complex interplay between social factors and excess weight in the second half of life. Future longitudinal studies are needed to clarify this relationship in further detail. 


\section{Abbreviations}

BMFSFJ: Federal Ministry for Family Affairs, Senior Citizens, Women and Youth; BMI: Body-mass-index; DEAS: German Ageing Survey; DZA: Deutsches Zentrum für Altersfragen; OECD: Organization for Economic Co-Operation and Development

\section{Acknowledgements}

Not applicable.

\section{Funding}

None.

\section{Availability of data and materials}

The data used in this study are third-party data. The anonymized data sets of the DEAS (1996, 2002, 2008, 2011, and 2014) are available for secondary analysis. The data has been made available to scientists at universities and research institutes exclusively for scientific purposes. The use of data is subject to written data protection agreements. Microdata of the German Ageing Survey (DEAS) is available free of charge to scientific researchers for non-profitable purposes. The FDZ-DZA provides access and support to scholars interested in using DEAS for their research. However, for reasons of data protection, signing a data distribution contract is required before data can be obtained. Please see for further Information (data distribution contract): https://www.dza.de/en/fdz/access-todata/formular-deas-en-english.html

\section{Authors' contributions}

AH, HHK: Design and concept of analyses, preparation of data, statistical analysis and interpretation of data, preparing of the manuscript. Both authors critically reviewed the manuscript, provided significant editing of the article and approved the final manuscript.

\section{Ethics approval and consent to participate}

Please note that an ethical statement for the DEAS study was not necessary as the criteria for requiring an ethical statement were not met (risk for the respondents, lack of information about the aims of the study, examination of patients). This is in accordance with the German Research Foundationguidelines (Deutsche Forschungsgemeinschaft, DFG) available at: http:// dfg.de/foerderung/faq/geistes_sozialwissenschaften/ (only available in German language).

The German Centre of Gerontology (DZA) decided that an ethical statement was not necessary. It is worth noting that the DEAS study has a permanent advisory board. Prior to each wave of data collection, the permanent advisory board receives detailed information about the sampling method, consent to participate and the instruments used in the DEAS study. The permanent advisory board concluded that the DEAS study did not need approval from an ethics committee. This procedure is in concordance with local guidelines. Please also see the RatSWD (Principles and Review Procedures of Research Ethics in the Social and Economic Sciences): https:// www.ratswd.de/dl/RatSWD_Output9_Forschungsethik.pdf, page 28 (only available in German language).

Prior to the interview, written informed consent was given by all participants of the study.

\section{Consent for publication}

Not applicable.

\section{Competing interests}

The authors declare that they have no competing interests.

\section{Publisher's Note}

Springer Nature remains neutral with regard to jurisdictional claims in published maps and institutional affiliations.

\section{Received: 1 November 2017 Accepted: 10 October 2018} Published online: 25 October 2018

\section{References}

1. Finucane MM, Stevens GA, Cowan MJ, Danaei G, Lin JK, Paciorek CJ, Singh GM, Gutierrez HR, Lu Y, Bahalim AN. National, regional, and global trends in body-mass index since 1980: systematic analysis of health examination surveys and epidemiological studies with 960 country-years and 9.1 million participants. Lancet. 2011:377(9765):557-67.

2. Lehnert T, Sonntag D, Konnopka A, Riedel-Heller S, König H-H. Economic costs of overweight and obesity. Best Pract Res Clin Endocrinol Metab. 2013; 27(2):105-15.

3. Mensink G, Schienkiewitz A, Haftenberger M, Lampert T, Ziese T, Scheidt-Nave C. Overweight and obesity in Germany: results of the German health interview and examination survey for adults (DEGS1). Bundesgesundheitsblatt, Gesundheitsforschung, Gesundheitsschutz. 2013;56(5-6):786-94.

4. Hajek A, Lehnert T, Ernst A, Lange C, Wiese B, Prokein J, Weyerer S, Werle J, Pentzek M, Fuchs A, et al. Prevalence and determinants of overweight and obesity in old age in Germany. BMC Geriatr. 2015;15(1):83.

5. Corica F, Bianchi G, Corsonello A, Mazzella N, Lattanzio F, Marchesini G. Obesity in the context of aging: quality of life considerations. Pharmacoeconomics. 2015;33(7):655-72.

6. Berry C, Gerry L, Hayward M, Chandler R. Expectations and illusions: a position paper on the relationship between mental health practitioners and social exclusion. J Psychiatr Ment Health Nurs. 2010;17(5):411-21.

7. Werner NS, Kerschreiter R, Kindermann NK, Duschek S. Interoceptive awareness as a moderator of affective responses to social exclusion. J Psychophysiol. 2013;27(1):39-50.

8. Schumaker JF, Krejci RC, Small L, Sargent RG. Experience of loneliness by obese individuals. Psychol Rep. 1985:57(3 suppl):1147-54.

9. Oliveira AJ, Rostila M, Leon AP, Lopes CS. The influence of social relationships on obesity: sex differences in a longitudinal study. Obesity. 2013;21(8):1540-7.

10. Fernández-Alonso AM, Trabalón-Pastor M, Vara C, Chedraui P, Pérez-López FR, Group MRAR. Life satisfaction, loneliness and related factors during female midlife. Maturitas. 2012;72(1):88-92.

11. Lee WJ, Youm Y, Rhee Y, Park Y-R, Chu SH, Kim HC. Social network characteristics and body mass index in an elderly Korean population. J Prev Med Public Health. 2013:46(6):336-45.

12. Wang ML, Pbert L, Lemon SC. Influence of family, friend and coworker social support and social undermining on weight gain prevention among adults. Obesity. 2014;22(9):1973-80.

13. Winston GJ, Phillips EG, Wethington E, Devine C, Wells M, Peterson JC Hippolyte J, Ramos R, Martinez G, Eldridge J. Social network characteristics associated with weight loss among black and hispanic adults. Obesity. 2015; 23(8):1570-6.

14. Zwickert K, Rieger E. A qualitative investigation of obese women's experiences of effective and ineffective social support for weight management. Clin Obes. 2014;4(5):277-86.

15. Sikorski C, Luppa M, Brähler E, König H-H, Riedel-Heller SG. Obese children, adults and senior citizens in the eyes of the general public: results of a representative study on stigma and causation of obesity. PLoS One. 2012; 7(10):e46924.

16. Lennon SJ, Lillethun A, Buckland SS. Attitudes toward social comparison as a function of self-esteem: idealized appearance and body image. Fam Consum Sci Res J. 1999:27(4):379-405.

17. Neller K. Kooperation und Verweigerung. Eine Non-Response-Studie. ZUMA Nachrichten. 2005;29(57):9-36.

18. Schiel S, Kerr P, Dickmann C, Aust F. Methodenbericht zur Durchführung der fünften Erhebungswelle 2014. Bonn: infas Institut für angewandte Sozialwissenschaft $\mathrm{GmbH} ; 2015$

19. Klaus D, Engstler H: Daten und Methoden des Deutschen Alterssurveys. In: Mahne K, Wolff JK, Simonson J, Tesch-Römer C. Altern im Wandel: Zwei Jahrzehnte Deutscher Alterssurvey (DEAS). Berlin: Springer; 2016. p. 25-42.

20. Bude $H$, Lantermann E-D. Soziale exklusion und exklusionsempfinden. KZfSS Kölner Zeitschrift für Soziologie und Sozialpsychologie. 2006;58(2):233-52.

21. Franke J, Simonson J. Social justice beliefs regarding old-age provisions in Germany: a latent profile analysis. Soc Justice Res. 2018;31(2):182-205.

22. Cameron AJ, Welborn TA, Zimmet PZ, Dunstan DW, Owen N, Salmon J, Dalton M, Jolley D, Shaw JE. Overweight and obesity in Australia: the 19992000 Australian diabetes, obesity and lifestyle study (AusDiab). Med J Aust. 2003;178(9):427-32.

23. Martínez-González MÁ, Alfredo Martinez J, Hu F, Gibney M, Kearney J. Physical inactivity, sedentary lifestyle and obesity in the European Union. Int J Obes Relat Metab Disord. 1999:23(11):1192-201.

24. Shelton NJ, Knott CS. Association between alcohol calorie intake and overweight and obesity in English adults. Am J Public Health. 2014; 104(4):629-31. 
25. Sicras-Mainar A, Rejas-Gutiérrez J, Navarro-Artieda R, Ibanez-Nolla J. Effect of smoking status on healthcare costs and resource utilization in patients with type 2 diabetes in routine clinical practice: a retrospective nested casecontrol economic study. Eur Addict Res. 2014;20(2):94-104.

26. Goodman E, Slap GB, Huang B. The public health impact of socioeconomic status on adolescent depression and obesity. Am J Public Health. 2003; 93(11):1844-50.

27. Radloff LS. The CES-D scale a self-report depression scale for research in the general population. Appl Psychol Meas. 1977;1 (3):385-401.

28. Hajek A, Brettschneider C, Lange C, Posselt T, Wiese B, Steinmann S, Weyerer S, Werle J, Pentzek M, Fuchs A, et al. Gender differences in the effect of social support on health-related quality of life: results of a population-based prospective cohort study in old age in Germany. Qual Life Res. 2016;25(5):1159-68.

29. Jackson SE, Beeken RJ, Wardle J. Perceived weight discrimination and changes in weight, waist circumference, and weight status. Obesity. 2014; 22(12):2485-8

30. Victor CR, Scambler SJ, Bowling A, Bond J. The prevalence of, and risk factors for, loneliness in later life: a survey of older people in Great Britain. Ageing Soc. 2005;25(06):357-75.

31. Farid S, Luqman M, Saleem MZ, Saad A, Khan WA, Arshad S, Warraich IA. Social isolation within family: an analysis of old age citizens. Br J Educ, Soc Behav Sci. 2014;4(9):1300-11

32. Sarlio-Lähteenkorva S, Lahelma E. The association of body mass index with social and economic disadvantage in women and men. Int J Epidemiol. 1999;28(3):445-9.

33. Hansson LM, Rasmussen F. Attitudes towards obesity in the Swedish general population: the role of one's own body size, weight satisfaction, and controllability beliefs about obesity. Body Image. 2014;11 (1):43-50.

34. Gorber SC, Tremblay M, Moher D, Gorber B. A comparison of direct vs. selfreport measures for assessing height, weight and body mass index: a systematic review. Obes Rev. 2007;8(4):307-26.

35. House JS, Landis KR, Umberson D. Social relationships and health. Science. 1988;241(4865):540.

Ready to submit your research? Choose BMC and benefit from:

- fast, convenient online submission

- thorough peer review by experienced researchers in your field

- rapid publication on acceptance

- support for research data, including large and complex data types

- gold Open Access which fosters wider collaboration and increased citations

- maximum visibility for your research: over $100 \mathrm{M}$ website views per year

At $\mathrm{BMC}$, research is always in progress.

Learn more biomedcentral.com/submissions 